\title{
Effects of Exogenous Melatonin in Clarias Macrocephalus Male Broodstock First Puberty Stage
}

Siti-Ariza Aripin ${ }^{1,2 *}$, Orapint Jintasataporn ${ }^{1}$ and Ruangvit Yoonpundh ${ }^{1}$

${ }^{1}$ Faculty of Fisheries, Kasetsart University, 10900, Bangkok, Thailand

${ }^{2}$ School of Fisheries and Aquaculture Sciences, Universiti Malaysia Terengganu, 21030, Terengganu, Malaysia

\begin{abstract}
The purpose of this study was to investigate the exogenous melatonin feeding administration to the first puberty stage in male broodstock of the Walking catfish, Clarias macrocephalus. The melatonin level of 0 (Control), 50 (Mt0.05) and 250 (Mt0.25) $\mathrm{mg} / \mathrm{kg}$ in the diet mixed in isonitrogenous and isocaloric of $37 \%$ crude protein and $9.3 \%$ crude lipid was applied. The male maturation analysis for this study comprised of gonad histology, testosterone assay, gonadosomatic index, sperm abnormality, live sperm rate, sperm concentration, and sperm kinetic parameters. Significant differences were found in maturation analysis $(P<0.05)$ compared with the control treatment. In addition, the histological analysis found that the mature spermatozoa cells were highest in the melatonin-treated male catfish. The present results showed that exogenous melatonin is able to enhance the reproductive system of male $C$. macrocephalus. The suitable exogenous melatonin level to enhance the Clarias macrocephalus male broodstock first puberty is Mt0.25 (50 mg/kg melatonin in the diet).
\end{abstract}

Keywords: Melatonin; Broodstock; First puberty; Male; Clarias macrocephalus

\section{Introduction}

Clarias macrocephalus (walking catfish) is one of the important fish species in Southeast Asia aquaculture industry. This species is now regarded in as near threatened by The International Union for Conservation of Nature (IUCN) Red List, because of disease susceptibility, hybrid catfish introduction, habitat fragmentation, low larval survival rate, low sperm quality and domestication problems $[1,2]$. Male catfish does not release semen by manual stripping and this has resulted in the sacrifice of male broodstock and removal of testis for artificial insemination of stripped eggs $[3,4]$. The circumstance of sufficient quality of C. macrocephalus semen will benefit the artificial propagation of walking catfish. Therefore, it is essential to enhance the first puberty stage and to increase the completion of spermatogenesis (spermiogenesis and spermiation) of walking catfish.

Photoperiod is one of the factors which regulate the animal rhythms including the reproductive cycle. The secretion of melatonin from the pineal gland is the effect from photoperiodic signals, and it affects the reproduction system [5]. It enhances the gonadotropinreleasing hormone $(\mathrm{GnRH})$ from the hypothalamus, and it exercises its function mainly on the hypothalamus-pituitary-gonad axis [6]. Based on research by Almeida et al., pubertal testis maturation teleost fish are controlled by the endocrine system with environmental signals such as photoperiod to regulate the changes in Gnrh release.

Melatonin administration might be useful in enhancing and initiate the first puberty stage of the testicular event. Nevertheless, the existing information on the effect of melatonin to testicular event is based mostly on male mammalian studies, where melatonin is known to enhance the male reproductive system in human, ram, rat, and buck [7-10]. In addition, previous studies in female teleost show that induce melatonin are able to stimulate the maturation-inducing hormone, oocytes maturation and embryo development $[11,12]$. According to Tan et al. [13], melatonin has the ability to metabolize different kinds of reactive oxygen and nitrogen species. It also stimulates the ability to preserves cell membrane fluidity [14]. The studies proved that melatonin antioxidative effects on spermatozoa have significantly reduces the rate of lipid peroxidation in sperm, and it can protect sperm mitochondria from the damage induced by reactive oxygen species (ROS) throughout its effective antioxidative effect $[15,16]$. To promote the understanding of the melatonin influence in male C. macrocephalus, this research investigated the effects of melatonin feeding administration in male broodstock of the C. macrocephalus.

\section{Materials and Methods}

\section{Animals}

The maiden C. macrocephalus male broodstock were obtained from the Fisheries Station of Kham Pheng Phet, Department of Fisheries, Ministry of Agriculture and Cooperative, Thailand. The experiment trials were conducted in the Laboratory of Nutrition and Aquafeed, Department of Aquaculture, Faculty of Fisheries, Kasetsart University, Bangkok, Thailand. The eighteen weeks old catfish were acclimatized in $500 \mathrm{~L}$ tanks at the density of $15 \mathrm{ind} / \mathrm{m}^{2} / \mathrm{fish} / \mathrm{tank}$ and fed with control feed for two weeks prior to the experiment. The source of water supply was provided with continuous aeration to maintain the oxygen supply in the experiment tank.

\section{Experimental diets}

Feeding trial used one control and two different levels of melatonin. The basal diet was formulated from practical ingredients containing $22 \%$ fishmeal, $35 \%$ soybean, $1 \%$ spirulina, $12 \%$ wheat flour, $11.8 \%$ tapioca, $5 \%$ ricebran, $2 \%$ fish oil, $3 \%$ soy oil, $1.2 \%$ mineral premix, $2 \%$ soy lecithin, $1.5 \%$ calcium phosphate, $1 \%$ attractant, $2 \%$ binder and

${ }^{*}$ Corresponding author: Siti-Ariza Aripin, School of Fisheries and Aquaculture Sciences, Universiti Malaysia Terengganu, 21030, Terengganu, Malaysia, Tel: +60104160016; E-mail: siti.ariza@umt.edu.my

Received November 23, 2014; Accepted December 16, 2014; Published January 18, 2015

Citation: Aripin SA, Jintasataporn O, Yoonpundh R (2015) Effects of Exogenous Melatonin in Clarias Macrocephalus Male Broodstock First Puberty Stage. J Aquac Res Development 6: 307. doi:10.4172/2155-9546.1000307

Copyright: @ 2015 Aripin S, et al. This is an open-access article distributed under the terms of the Creative Commons Attribution License, which permits unrestricted use, distribution, and reproduction in any medium, provided the original author and source are credited. 
$0.5 \%$ vitamin premix. The diet also consisted of $37 \%$ crude protein and $9.3 \%$ crude lipid. Diets containing melatonin were prepared by adding graded levels of melatonin (Health Connection Labs Inc, USA) to the basal diet. These melatonin concentrations were 0 (control), 50 (Mt0.05) and 250 (Mt0.25) $\mathrm{mg} / \mathrm{kg}$ in the diet [17].

\section{Experimental condition}

A total of 45 male of mean weight $57.43 \pm 5.58 \mathrm{~g}$ (mean \pm S.D.) were starved in tanks for two days prior to the experiment and all experiment population were subjected to normal photoperiod $(12$ hours daylight) and temperature (varied from $28^{\circ} \mathrm{C}$ to $30^{\circ} \mathrm{C}$ ) prior and during the treatment. The fishes were fed twice daily with pellet feed at a level equivalent to $3 \%$ of their body weight. The fishes were randomly distributed in three treatments (control, Mt0.05 and Mt0.25) and with three replicates. Following acclimation, the fishes were exposed to melatonin feeding treatments for eight weeks.

\section{Growth performance}

Male broodstock was weighted before the final sampling to determine the growth performance by using the following formula:

Weight gain: WG (\%)=[(Final body weight-Initial body weight $) /$ Initial body weight $] \times 100$

\section{Histology}

The sacrificed males from the treatment were dissected, and testes were fixed in $10 \%$ buffered formalin. Histological slides were made by using the standard paraffin technique where tissue samples were collected from the mid-part of the gonad. The 3-6 $\mu \mathrm{m}$ sections were stained with Haematoxylin-eosin in accordance to Drury and Wallington [18].

\section{Immunohistochemistry}

The 10\% buffered formalin fixed brains were processed by following the standard method by Carvajal et al. [19]. All sections were preincubated for 30 minutes in normal goat serum (Sigma) at a dilution

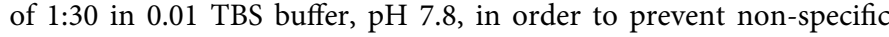
protein binding. The sections were incubated in goat anti-melatonin (Abcam, UK) at a dilution of 1:5000 in TBS buffer for 24 hours at $4^{\circ}$ C.DAB Liquid Substrate Dropper System Kit (Sigma) was done for sections staining to localize peroxidase in tissue sections by following the method of Graham and Karnovsky [20].

\section{Characteristics of semen and spermatozoa}

Testes from the treatment fishes were surgically removed and were cut in small pieces to allow sperm release after gentle squeezing. Semen was stored with an extender solution in sterile Eppendorf tubes on ice before use. Composition of extenders was as follows: $\mathrm{NaCl} 8.760 \mathrm{~g}$ in $1000 \mathrm{ml}$ distilled water [21].

Live sperm rate and sperm concentration: Eosin-nigrosin stained semen smears were evaluated with brightfield microscopy for the live cells by counting 400 cells per sample. Sperm concentration was determined in duplicate and expressed as the number of spermatozoa $\times 10^{6} / \mathrm{ml}$. Number of spermatozoa was counted in improved Neuber haemacytometer under a light microscope.

Sperm kinetic characteristic: Kinetic characteristics were evaluated immediately after semen collection. Ten microlitres of the samples were diluted 1:1 with the extender solution and were laid over a pre-warmed Hamilton Thorne Biosciences chamber at $27.8^{\circ} \mathrm{C}$. The analyses were done by Computer-Assisted Sperm Analysis (CASA). The recorded sperm parameters were $[22,23]$ :

$>$ motility $(\%)=$ the percentage of motile spermatozoa;

$>$ progressive $(\%)=$ the percentage of spermatozoa with a progressive motility;

path velocity (VAP; $\mu \mathrm{m} / \mathrm{s})=$ is a smoothed path constructed by averaging several neighbouring positions on the track (five points) and joining the averaged positions, which reduced the effect of lateral head displacement;

$>$ prog. velocity $(\mathrm{VSL} ; \mu \mathrm{m} / \mathrm{s})=$ is the straightline distance between the first and last tracked points, divided by the acquisition time;

$>$ track speed or curvilinear velocity $\left(\mathrm{VCL} ; \mu \mathrm{m} \bullet \mathrm{s}^{-1}\right)=$ is the total distance between adjacent points, divided by the time elapsed;

$>$ lateral amplitude $(\mathrm{ALH} ; \mu \mathrm{m})=$ the mean width of the head oscillation as the sperm cells swim;

$>$ beat frequency $(\mathrm{BCF} ; \mathrm{Hz})=$ frequency of sperm head crossing the average path in either direction;

$>$ straightness (STR; \%)=is an index of the departure of the sperm path from a straight line;

$>\quad$ linearity $(\mathrm{LIN} ; \%)=$ is an index of the straightness of the path

Sperm abnormality: Fresh semen in extender solution was stained within 10 minutes of post collection. Eosin-nigrosin stained semen smears were evaluated by bright field microscopy at x 1000 magnification under oil immersion, and the percentages of abnormal and normal sperm cells were determined.

\section{Gonadosomatic index}

After feeding treatments for eight weeks, male C. macrocephalus were randomly selected from each treatment to measure body weight and testes weight. Then, the GSI (Mean \pm S.D.\%) of each individual was calculated (King, 1995).

The Gonadosomatic Index was determined as:

$\mathrm{GSI}=100(\mathrm{Gm} / \mathrm{Tm})$

where;

Gm=Mass of Gonad, Tm=Total mass of fish

\section{Testosterone analysis}

The serum from treatments was used for testosterone analysis. The procedure was in accordance to the IMMULITE ${ }^{-}$Testosterone by Siemens Medical Solution Diagnostic standard procedure with the detection range from $0.2-15 \mathrm{ng} / \mathrm{ml}$ of testosterone level. The testosterone enzymes conjugate competes with $20 \mu \mathrm{l}$ of serum samples, and the chemiluminescent substrate was added and the signal was generated according to the bound enzyme.

\section{Statistical analysis}

All data were analyzed by one-way ANOVA (analysis of variance), followed by the Tukey's honest significance test to analyze the significant between the treatment means. Duncan test was done when Tukey's honest significant test failed to analyze the significant between treatment means. All means comparisons significance was tested at $\mathrm{P}<0.05$ using SPSS software. 


\section{Results}

Melatonin trial did not significantly affect the weight gain between treatments where the weight gain was $10.94 \%$ (control), $15.55 \%$ (Mt0.05) and 16.98\% (Mt0.25) with the value at $\mathrm{p}=0.1$. Meanwhile, histological analysis is a useful tool for description of the testis after hormonal treatment where histological changes in testes during the melatonin trial were observed in C. macrocephalus (Figure 1). It was established in the present study that the control group demonstrates the most abundance in spermatogonium which was $33.9 \%$ (control), followed by $23 \%(\mathrm{Mt} 0.05)$ and $9.2 \%(\mathrm{Mt} 0.25)$ (Figure $1 \mathrm{~A}$ and Table $1)$. On the other hand, spermatids were prominent in Mt0.05 group (28.4\%), followed by control group (27.3\%) and Mt0.25 group (5.4\%) (Figure 1B and Table 1). Spermatozoa were found mainly in Mt0.25 group (85.4\%), followed by Mt0.05 group (48.6\%) and control group (38.8\%) (Figure 1C and Table 1).

Treatment with melatonin increased the gonadosomatic index, live sperm rate and lowered the sperm abnormality rate. The significant level of melatonin on male gonadosomatic index, sperm abnormality and live sperm rate were $\mathrm{p}=0.001, \mathrm{p}=0.001$ and $\mathrm{p}=0.001$, respectively (Figures 2A-2C, 3 and Table 1). However, exogenous melatonin

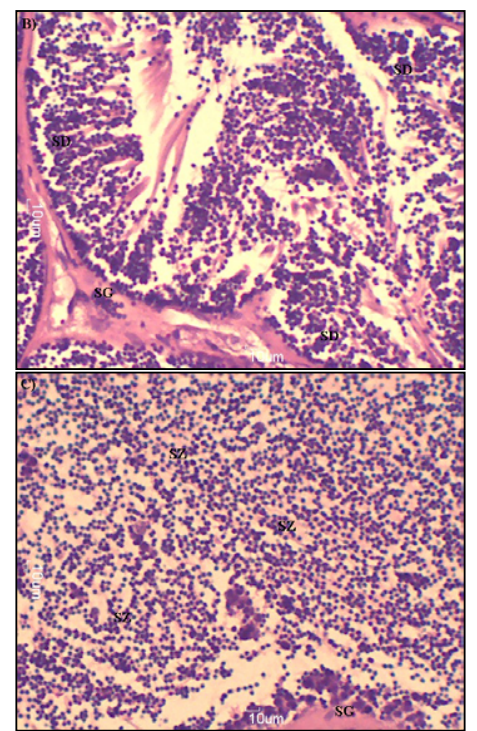

Figure 1: Effect of melatonin treatment on testis histology of the $C$ macrocephalus. Cross section of testis treated melatonin and control: A) Control, B) Mt0.05 and C) Mt0.25. Spermatogonia (SG), spermatids (SD), and spermatozoa (SZ) scale bar: $100 \mu \mathrm{m}$.

\begin{tabular}{|l|c|c|c|c|}
\hline Parameters & Control & Mt0.05 & Mt0.25 & $\begin{array}{c}P \\
\text { value }\end{array}$ \\
\hline Weight gain (\%) & $10.94 \pm 5.8$ & $15.55 \pm 7.6$ & $16.98 \pm 12.5$ & 0.1 \\
\hline Histology spermatogonium cell & $33.90 \%$ & $23 \%$ & $9.20 \%$ & - \\
\hline Histology spermatids cell & $27.30 \%$ & $28.40 \%$ & $5.40 \%$ & - \\
\hline Histology spermatozoa cell & $38.80 \%$ & $48.60 \%$ & $85.40 \%$ & - \\
\hline Gonadosomatic index Mean (\%) & $0.425^{\mathrm{b}} \pm 0.07$ & $0.582^{\mathrm{a}} \pm 0.07$ & $0.677^{\mathrm{a}} \pm 0.11$ & 0.001 \\
\hline Sperm abnormality Mean (\%) & $30.8^{\mathrm{b}} \pm 7.5$ & $15^{\mathrm{b}} \pm 4.8$ & $7.6^{\mathrm{a}} \pm 3.3$ & 0.001 \\
\hline Live sperm rate (\%) & $18.7^{\mathrm{b}} \pm 18.7$ & $80.3^{\mathrm{a}} \pm 21.2$ & $92.5^{\mathrm{a}} \pm 5.4$ & 0.001 \\
\hline Sperm concentration (10 $/ \mathrm{ml})$ & $220.3 \pm 269$ & $127.3 \pm 104$ & $133.3 \pm 56$ & 0.5 \\
\hline Testosterone $(\mathrm{ng} / \mathrm{ml})$ & $13.45 \pm 2.7$ & $15>$ & $15>$ & - \\
\hline
\end{tabular}

a,b Values with different superscripts in a row differ significantly $(P<0.05)$.

Table 1: Maturation analysis in male C. macrocephalus with different levels of melatonin (Mean \pm S.E.)

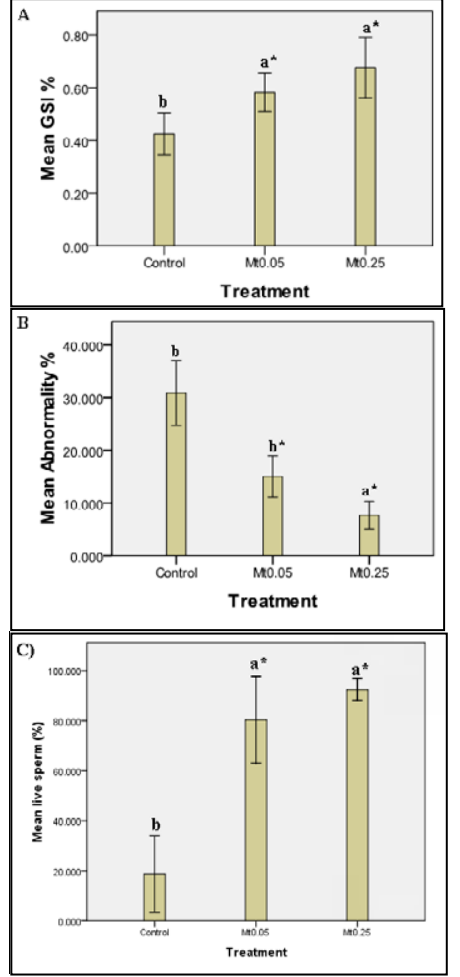

Figure 2: Mean gonadosomatic index (A), mean sperm abnormality (B), and live sperm rate $(C)$ of male $C$. macrocephalus after eight weeks of melatonin treatment. Values are expressed as mean \pm SEM $p<0.05$.

treatments did not alter the sperm concentration with the mean ranged from $127.3-22036 / \mathrm{ml} ; \mathrm{p}=0.5$. The investigation demonstrated that Mt 0.25 was the optimum melatonin dosage because of the highest GSI, live sperm rate and lowest abnormality percentage.

Testosterone levels after eight weeks of treatment in male C. macrocephalus were not calculated for ANOVA analysis because the level of testosterone was beyond the chemiluminescent assay detection range. The detection range of testosterone level for chemiluminescent assay is from $0.2-15 \mathrm{ng} / \mathrm{ml}$. In this current study, testosterone level for control was $13.45 \mathrm{ng} / \mathrm{ml}$, while the testosterone level for melatonin treated catfish was $15>\mathrm{ng} / \mathrm{ml}$ (Mt0.05 and Mt0.25) (Table 1).

Melatonin trial was performed on the C. macrocephalus male broodstock to evaluate the effects of melatonin administration on brain immunohistochemistry. There were differences after eight weeks of treatment in melatonin intensity for immunohistochemistry slide sections between the treatments. The intense melatonin-like immunoreactivity in the brain section was found in melatonin treatment groups compared to the control treatment (Figure 4). The response was distinct in forebrain zone, pineal gland immediate zone and the brain wall of male broodstock.

After the experiment trial, there was a significant increment in sperm motility (Figure 5A) and sperm progressive (Figure 5B) among male fish in the presence of melatonin treatment after eight weeks of treatment where the mean ranged from $4.0-12.5 \% ; \mathrm{p}=0.004$ and $1-2 \%$; $\mathrm{p}=0.048$, respectively (Table 2 ). Dietary melatonin treatments did not alter the kinetic parameters such as sperm path velocity, prog. velocity, track speed, lateral amplitude, beat frequency, straightness, and 


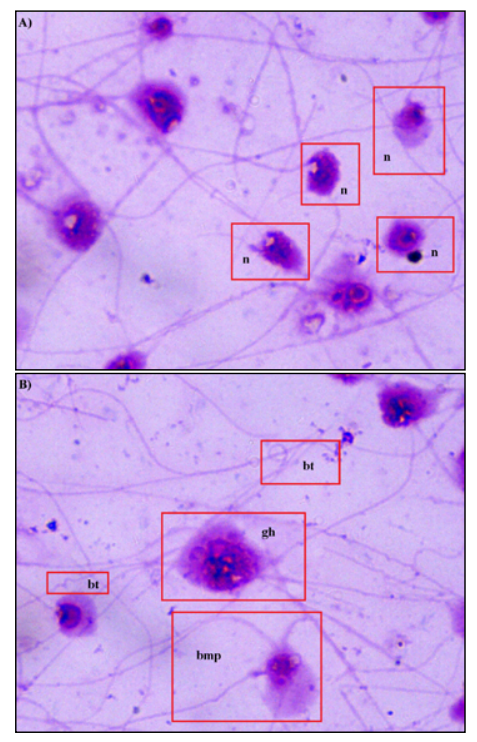

Figure 3: Some of the sperm abnormality traits in melatonin treatment of the male C. macrocephalus. A) Normal C. macrocephalus spermatozoa. B) Abnormal C. macrocephalus spermatozoa. Normal ( $\mathrm{n})$, bend tail (bt), giant head $(\mathrm{gh})$, bowed midpiece (bmp).

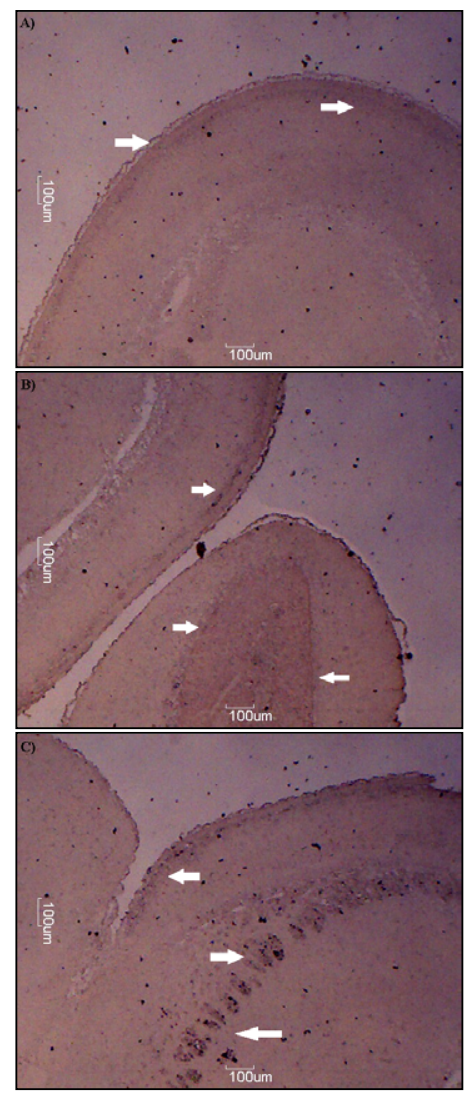

Figure 4: Light micrograph of the $C$. macrocephalus brain section incubated with anti-melatonin (dilution $1 / 5000$ ) and DAB staining. Cross section of fish treated brains with control (A), Mt0.05 (B) and Mt0.25 (C). Note arrow for the intense reaction at the brain section. Scale bar $=100 \mu \mathrm{m}$.

linearity with the mean ranged from $42.8-48.9 \mu \mathrm{m} / \mathrm{s} ; \mathrm{p}=0.3,34.8-39.4$ $\mu \mathrm{m} / \mathrm{s} ; \mathrm{p}=0.4,67.1-71.7 \mu \mathrm{m} / \mathrm{s} ; \mathrm{p}=0.8,5.6-7.3 \mu \mathrm{m} ; \mathrm{p}=0.5,29.5-32.0 \mathrm{~Hz}$; $\mathrm{p}=0.7,79.2-80.3 \% ; \mathrm{p}=0.9$, and $52.7-57.2 \% ; \mathrm{p}=0.5$, respectively (Table 2 ).

\section{Discussion}

It is understood that photoperiod manipulation is associated with melatonin treatment where photoperiod modulates the melatonin secretion by the pineal gland. It has been supported in the present study that the levels of GSI from both melatonin groups demonstrated a significant influence during the experiment trial compared to the control group. Similar findings have been reported in human, rams, rats, carp [24]. In recent histological study, the spermatogonia cells are abundance in the control group indicating that the testicular event in the group is immature. Spermatids and spermatozoa are more prominent in the male that were exposed to both doses of melatonin which indicates that both treatment enhanced the maturity of male C. macrocephalus and the results were consistent with the increase of GSI percentage. There were evidences from the previous studies that melatonin acts as an important part in the regulation of testicular events [25]. Although melatonin has an effect on spermatogenesis, more information is still needed. Some previous works have indicated that melatonin act in the reproductive axis through direct action on the Gonadotropin-releasing hormone $(\mathrm{GnRH})$ gene expression and its regulation with the melatonin receptors on the $\mathrm{GnRH}$ neurons

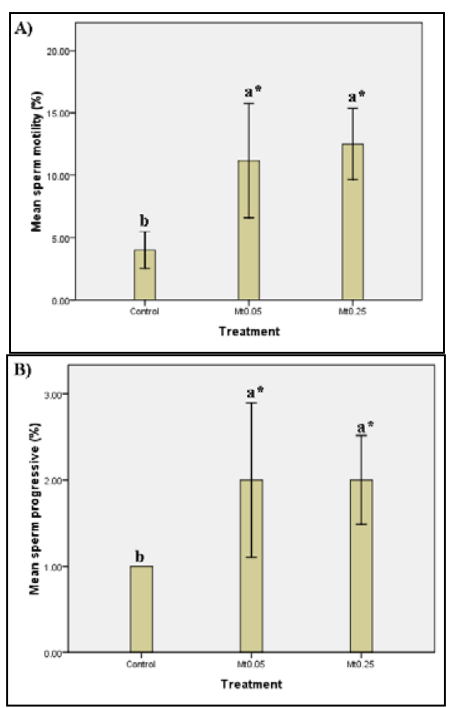

Figure 5: Mean sperm motility (A) and mean sperm progressive (B) of male C. macrocephalus after eight weeks of melatonin treatment. Values are expressed as mean \pm SEM. $p<0.05$.

\begin{tabular}{|l|c|c|c|c|}
\hline Parameters & Control & Mt0.05 & Mt0.25 & $P$ value \\
\hline Motility $(\%)$ & $4.0^{\mathrm{b}} \pm 1.8$ & $11.2^{\mathrm{a}} \pm 5.6$ & $12.5^{\mathrm{a}} \pm 3.5$ & 0.004 \\
\hline Progressive $(\%)$ & $1^{\mathrm{b}} \pm 0$ & $2^{\mathrm{a}} \pm 1.1$ & $2^{\mathrm{a}} \pm 0.6$ & 0.048 \\
\hline Path velocity $(\mathrm{VAP})(\mu \mathrm{m} / \mathrm{s})$ & $42.8 \pm 4.3$ & $48.7 \pm 8.1$ & $48.9 \pm 11.6$ & 0.3 \\
\hline Prog. velocity $(\mathrm{VSL})(\mu \mathrm{m} / \mathrm{s})$ & $34.8 \pm 3.6$ & $38.3 \pm 4.4$ & $39.4 \pm 10.1$ & 0.4 \\
\hline Track speed $(\mathrm{VCL})(\mu \mathrm{m} / \mathrm{s})$ & $67.1 \pm 9.8$ & $68.4 \pm 12.4$ & $71.7 \pm 19$ & 0.8 \\
\hline Lateral amplitude $(\mathrm{ALH})(\mu \mathrm{m})$ & $5.6 \pm 2.4$ & $6.2 \pm 2.4$ & $7.3 \pm 2.9$ & 0.5 \\
\hline Beat frequency $(\mathrm{BCF})(\mathrm{Hz})$ & $29.5 \pm 7.5$ & $32.0 \pm 4.8$ & $29.9 \pm 4.2$ & 0.7 \\
\hline Straightness $(\mathrm{STR})(\%)$ & $79.2 \pm 14$ & $79.5 \pm 7.4$ & $80.3 \pm 5.4$ & 0.9 \\
\hline Linearity $(\mathrm{LIN})(\%)$ & $52.7 \pm 6.8$ & $54.0 \pm 9.6$ & $57.2 \pm 4.6$ & 0.5 \\
\hline
\end{tabular}

a,b Values with different superscripts in a row differ significantly $(P<0.05)$.

Table 2: Sperm kinetic parameters measured by CASA for male $C$. macrocephalus with different levels of melatonin $(P<0.05)$ (Mean \pm S.E.) 
of the hypothalamus [26]. This would have increased the luteinizing hormone (GTH-II) and follicle-stimulating hormone (GTH-I); with the confirmation from previous study that in vitro melatonin study stimulated GTH-II and GTH-I release from pituitary cells [27]. This indicates that melatonin may significantly elevate plasma GTH-II and GTH-I levels where it mainly regulates gonadal maturation and spermiation process. Schulz et al. [28] reported that GTH-II and GTH-I are the most significant pituitary hormones that regulate testicular physiology. In mammals, GTH-II regulates Leydig cell sex steroid production and GTH-I regulate the Sertoli cell activities [29].

For immunohistochemistry analysis, the brain sections from female broodstock that were treated with melatonin displayed more intense colouration area compared to the control treatment. The similar display was found in mammals. The high intensity of melatonin in treated broodstock occurs due to melatonin absorption from the treated fed. The melatonin treated fed is absorbed in the digestive system via transcellular pathway [30]. According to Zeuthen [31], transcellular pathway is a type of molecules transport that flows across both basal and apical membranes, which occurs in response to the osmotic stimuli created by salt transport, by entering the bloodstream and goes to the target organ such as brain and peripheral tissues.

According to Langford et al. [32], melatonin stimulates spermatogenic activity by increasing the sensitivity of Leydig cells to GTH-II. Besides enhancing the maturation via pituitary-hypothalamusgonad axis, melatonin also acts as directly on the testes through Leydig cells [33]. Therefore, GTH-II regulates Leydig cell sex steroid production such as testosterone. The stimulation of live sperm rate, sperm motility, enhanced some of the CASA parameters and lowered the sperm abnormality by melatonin treatment might be caused by the enhancement of the production of testosterone. Testosterone in the testis is essential for spermatogenesis which regulates the spermatogenesis, maintaining the blood-testis barrier and releasing the mature sperm [34]. Additionally, testosterone could increase sperm quality by inhibiting the spermatocyte and spermatide apoptosis [35].

\section{Conclusion}

For the first time, this study shows that melatonin feeding treatment to male C. macrocephalus has significantly improved the first puberty event by enhancing the maturation of testes and sperm. The study recommended that the Mt0.25 is the optimum level to enhance the Clarias macrocephalus male broodstock first puberty. The results obtained from the present study provide information on melatonin enhancement to male reproductive system that will lead to more efficient gamete management and may increase yield of catfish in the aquaculture industry.

\section{Acknowledgement}

The authors would like to thank all members of Laboratory of Nutrition and Aquafeed, Department of Aquaculture, Faculty of Fisheries, Kasetsart University, Bangkok for their kind assistance during this study. This study was funded by Ministry of Education, Malaysia.

\section{References}

1. Petkam R, Moodie GEE (2001) Food particle size, feeding frequency, and the use of prepared food to culture larval walking catfish (Clarias macrocephalus). Aquaculture 194: 349-362.

2. Vuthiphandchai V, Thadsri I, Nimrat S (2009) Chilled storage of walking catfish (Clarias macrocephalus) semen. Aquaculture 296: 58-64

3. Mansour N, Lahnsteiner F, Berger B (2004) Characterization of the testicular semen of the African catfish, Clarias gariepinus (Burchell, 1822), and its shortterm storage. Aquac Res 35: 232-244.
4. Viveiros ATM, Fessehaye Y, ter Veld M, Schulz RW, Komen J (2002) Handstripping of semen and semen quality after maturational hormone treatments, in African catfish Clarias gariepinus. Aquaculture 213: 373-386.

5. Falcon J, Migaud H, Muñoz-Cueto JA, Carrillo M (2010) Current knowledge on the melatonin system in teleost fish. Gen Comp Endocrinol 165: 469-482.

6. Falcon J, Besseau L, Sauzet S, Boeuf G (2007) Melatonin effects on the hypothalamo-pituitary axis in fish. Trends Endocrinol Metab 18: 81-88.

7. Awad H, Halawa $F$, Mostafa $T$, Atta $H$ (2006) Melatonin hormone profile in infertile males. Int J Androl 29: 409-413.

8. Casao A, Mendoza N, Perez-Pe R, Grasa P, Abecia J, et al. (2010) Melatonin prevents capacitation and apoptotic-like changes of ram spermatozoa and increases fertility rate. J Pineal Res 48: 39-46.

9. Drago $F$, Busa $L$ (2000) Acute low doses of melatonin restore full sexual activity in impotent male rats. Brain Res. 878: 98-104.

10. Daramola JO, Adeloye AA, Fayeye TR, Fatoba TA, Soladoye AO (2006) Influence of photoperiods with or without melatonin on spermiograms in West African dwarf bucks. World J Zool 1: 86-90.

11. Chattoraj A, Bhattacharyya S, Basu D, Bhattacharya S, Bhattacharya S, et a (2005) Melatonin accelerates maturation inducing hormone (MIH): induced oocyte maturation in carps. Gen Comp Endocrinol 140: 145-155.

12. Danilova N, Krupnik VE, Sugden D, Zhdanova IV (2004) Melatonin stimulates cell proliferation in zebrafish embryo and accelerates its development. FASEB J 18: 751-753.

13. Tan DX, Reiter RJ, Manchester LC, Yan MT, El-Sawi M, et al. (2002) Chemical and physical properties and potential mechanisms: melatonin as a broad spectrum antioxidant and free radical scavenger. Curr Top Med Chem 2: 181-197.

14. Ashrafi I, Kohram H, Ardabili FF (2013) Antioxidative effects of melatonin on kinetics, microscopic and oxidative parameters of cryopreserved bull spermatozoa. Anim Reprod Sci 139: 25-30.

15. Gavella M, Lipovac V (2000) Antioxidative effect of melatonin on human spermatozoa. Arch Androl 44: 23-27.

16. Shang X, Huang Y, Ye Z, Yu X, Gu W (2004) Protection of melatonin against damage of sperm mitochondrial function induced by reactive oxygen species. Zhonghua Nan Ke Xue 10: 604-607.

17. Rubio VC, Sanchez-Vazquez FJ, Madrid JA (2004) Oral administration of melatonin reduces food intake and modifies macronutrient selection in European sea bass (Dicentrarchus labrax, L.). J Pineal Res 37: 42-47.

18. Drury RA, Wallington EA (1980) Carleton's Histological Technique. Oxford University Press, USA.

19. Carvajal JC, Esteban MBG, Carbajo S, Munoz-Barragan L (2004) Melatoninlike immunoreactivity in the pineal gland of the cow: an immunohistochemical study. Histol Histopathol 19: 1187-1192.

20. Graham RC, Karnovsky MJ (1966) The early stages of absorption of injection horseradish peroxidases in the proximal tubules of mouse kidney: Ultrastructural cytochemistry by a new technique. J. Histochem Cytochem 14: 291-302.

21. Sprecher DJ, Coe PH, Walker RD (1999) Relationships among seminal culture seminal white blood cells, and the percentage of primary sperm abnormalities in bulls evaluated prior to the breeding season. Theriogenology 51:1197-1206.

22. Katebi M, Movahedin M, Abdolvahabi MA, Akbari M, Abolhassani $F$, et al. (2005) Changes in motility parameters of mouse spermatozoa in response to different doses of progesterone during course of hyperactivation. Iran Biomed J 9: 73-79.

3. Klimowicz MD, Nizanski W, Batkowski F, Savic MA (2008) The comparison of assessment of pigeon semen motility and sperm concentration by conventional methods and the CASA system (HTM IVOS). Theriogenology 70: 77-82

24. Lombardo F, Gioacchini G, Fabbrocini A, Candelma M, D'Adamo R, et al. (2014) Melatonin-mediated effects on killifish reproductive axis. Comp Biochem Physiol 172: 31-38

25. Bhattacharya S, Chattoraj A, Maitra SK (2007) Melatonin in the regulation of annual testicular events in carp Catla catla: evidence from the studies on the effects of exogenous melatonin, continuous light, and continuous darkness. Chronobiol Int 24: 629-650.

26. Roy D, Angelini NL, Fujieda H, Brown GM, Belsham DD (2001) Cyclical 
Citation: Aripin SA, Jintasataporn O, Yoonpundh R (2015) Effects of Exogenous Melatonin in Clarias Macrocephalus Male Broodstock First Puberty Stage. J Aquac Res Development 6: 307. doi:10.4172/2155-9546.1000307

regulation of $\mathrm{GnRH}$ gene expression in GT1-7 GnRH-secreting neurons by melatonin. Endocrinology 142: 4711-4720.

27. Aizen J, Kowalsman N, Niv MY, Levavi-Sivan B (2014) Characterization of tilapia (Oreochromis niloticus) gonadotropins by modeling and immunoneutralization. Gen Comp Endocrinol 207: 28-33.

28. Schulz RW, Franca LR, Lareyre J, LeGac F, Chiarini-Garcia H, et al. (2010) Spermatogenesis in fish. Gen Comp Endocrinol 165: 390-411.

29. Huhtaniemi IT, Themmen AP (2005) Mutations in human gonadotropin and gonadotropin receptor genes. Endocrine 26: 207-217.

30. Tran HTT, Tran PHL, Lee B (2009) New findings on melatonin absorption and alterations by pharmaceutical excipients using the Ussing chamber technique with mounted rat gastrointestinal segments. Int J Pharm 378: 9-16.
31. Zeuthen T (2002) General models for water transport across leaky epithelia. Int Rev Cytol 215: 285-317.

32. Langford GA, Ainsworth L, Marcus G, Shrestha JNB (1987) Photoperiod entrainment of testosterone, luteinizing hormone, follicle stimulating hormone and prolactin cycles in rams in relation to testis size and semen quality. Biol Reprod 37: 489-499.

33. Shiu S, Yu Z, Chow P, Pang S (1996) Putative melatonin receptors in the male reproductive tissues. In: Tang $\mathrm{P}$, Pang S, Reiter R, (eds) Melatonin a universal photoperiodic signal with diverse actions. AG, Hong Kong Karger 21: 90-100

34. Walker WH (2009) Molecular mechanisms of testosterone action in spermatogenesis. Steroids 74: 602-607.

35. Ruwanpura SM, McLachlan RI, Meachem SJ (2010) Hormonal regulation of male germ cell development. J Endocrinol 205: 117-131. 